autonomic symptoms and in whom all autonomic function tests yielded normal results showed considerable falls in airway conductance after matched challenges. Their response did not differ from that of the non-diabetic controls. The results confirm that vagal pathways have a major role in the nonasthmatic response to bronchial cooling.

Autonomic neuropathy occurring in diabetic subjects may produce severe symptoms relating to the cardiovascular, gastrointestinal, and genitourinary systems, and objective testing can readily confirm dysfunction. Symptoms relating to the respiratory system are less apparent. Douglas et al have shown, however, that, in subjects in whom the respiratory system is affected, anticholinergic agents do not have a bronchodilator effect, implying that resting airway vagal tone is reduced owing to the respiratory branches of the vagus nerve being affected by the neuropathy. As baseline airway calibre is not affected in these subjects neurally mediated mechanisms of bronchoconstriction may be investigated without the use of pharmacological agents.

Attempts to study the role of vagal pathways in bronchial reactivity using anticholinergic agents have produced conflicting results. Different groups have used widely different doses or routes of administration of either atropine or ipratropium bromide, and all such studies are open to the criticism that any protection afforded by cholinergic blockade is due entirely to the change in baseline airway calibre produced by the bronchodilator action of the drugs. ${ }^{13}$ We have previously suggested that, in subjects who do not have asthma, bronchial responses to cold air are vagally mediated, ${ }^{414}$ and the present study confirms this view. Also, in a recent study, Jammes et al showed that in anaesthetised cats the increase in lung resistance induced by the inhalation of cold air could be abolished by sectioning the superior laryngeal and vagus nerves, ${ }^{15}$ further confirming our conclusion.
Finally, we have speculated that impaired, protective respiratory reflexes such as we have shown in this study may perhaps be implicated in the unexpected cardiorespiratory arrests that have been reported to occur in diabetic subjects with autonomic neuropathy. ${ }^{16}$

\section{References}

'American Thoracic Society. A statement by the committee on diagnostic standards for non-tuberculous respiratory diseases. Am Rev Respir Dis 1962;85:762-8.

Hargreave FE, Ryan G, Thomson NC, et al. Bronchial responsiveness to histamine or methacholine in asthma: measurement and clinical significance. $\mathcal{f}$ Allergy Clin Immunol $1981 ; 68: 347-55$.

'O'Byrne PM, Ryan G, Morris M, et al. Asthma induced by cold air and its relation to non-specific bronchial responsiveness to metacholine. Am Rev Respir Dis 1982;125:281-5.

'Heaton RW, Henderson AF, Gray BJ, Costello JF. The bronchial response to cold air challenge: evidence for different mechanisms in normal and asthmatic subjects. Thorax 1983;38:506-11.

Sheppard D, Epstein J, Holtzman MJ, Nadel JA, Boushey HA. Dose-dependent 1982;53:169-74.

'Griffen MP, Fung KF, Ingram RH, McFadden ER, Dose-response effects of atropine on thermal stimulus response relationship in asthma. $\mathcal{F}$ Appl Physiol $1982 ; 53: 1576-82$.

: O'Byrne PM, Thomson NC, Morris M, Roberts RS, Daniel EE, Hargreave FE. The protective effect of inhaled chlorpheniramine and atropine on bronchoconstriction stimulated by airway cooling. Am Rev Respir Dis 1983;128:611-7.

Douglas NJ, Campbell IW, Ewing DJ, Clarke BF, Flenley DC. Reduced airway vagal tone in diabetic subjects with autonomic neuropathy. Clin Sci $1981 ; 61$ : $581-4$.

${ }^{9}$ Cotes JE. Lung function. 4th ed. London: Blackwell Scientific Publications, 1979. pathy. The diagnostic value of heart rate monitoring. Diabetologia 1980;18: pathy.

Levin AB. A simple test for cardiac function based upon the heart rate changes induced by the valsalva manoeuvre. Am f Cardiol 1966;18:90-9.

Wieling W, van Brederode JFM, de Rij RCG, et al. Reflex control of heart rate in normal subjects in relation to age: a data base for cardiac vagal neuropathy. Diabetologia 1982;22:163-6.

${ }^{13}$ Benson MK. Bronchial hyper-reactivity. Br 7 Dis Chest 1975;69:227-39.

Henderson AF, Heaton RW, Costello JF. Effect of nifedipine on bronchoconstriction induced by inhalation of cold air. Thorax $1983 ; 38: 512-5$.

Jammes Y, Barthelemy P, Delpierre S. Respiratory effects of cold air breathing in anaesthetised cats. Respir Physiol 1983;54:41-54

${ }^{16}$ Ewing DJ, Campbell IW, Clarke BF. The natural history of diabetic autonomic neuropathy. $Q \mathcal{F}$ Med 1980;49:95-108.

(Accepted 4 May 1984)

\title{
Anti-Jo-1 antibody: a marker for myositis with interstitial lung disease
}

\author{
R M BERNSTEIN, S H MORGAN, J CHAPMAN, C C BUNN, M B MATHEWS, \\ $M$ TURNER-WARWICK, G R V HUGHES
}

\begin{abstract}
An autoantibody known as anti-Jo-1 antibody is found in $25 \%$ of patients with myositis. Its prevalence in patients
\end{abstract}

Rheumatology Unit, Hammersmith Hospital, London W12 0HS

R M BERNSTEIN, MA, MRCP, senior registrar and tutor in medicine

S H MORGAN, MB, MRCP, honorary registrar

C C BUNN, MIBIOL, research assistant

G R V HUGHES, MD, FRCP, consultant physician and reader in rheumatology

Cardiothoracic Institute, Brompton Hospital, London SW3

J CHAPMAN, MA, MRCP, research fellow

M TURNER-WARWICK, MD, FRCP, professor of medicine

Cold Spring Harbor Laboratory, Cold Spring Harbor, NY 11724, USA

M B MATHEWS, PHD, senior scientist

Correspondence to: Dr R M Bernstein. with both myositis and cryptogenic fibrosing alveolitis was $68 \%$ (13 out of 19 patients), compared with $7.5 \%$ in patients with myositis alone (four of 53) and $3 \%$ in patients with cryptogenic fibrosing alveolitis alone (two of 62 ).

Anti-Jo-1 antibody may be useful in indicating patients with myositis and cryptogenic fibrosing alveolitis. Raynaud's phenomenon, the sicca syndrome, and mild arthritis are also often part of the syndrome.

\section{Introduction}

Anti-Jo-1 antibody, an autoantibody directed at the cellular enzyme histidyl-tRNA synthetase, ${ }^{1}$ is found in $25 \%$ of patients with myositis but not in other myopathies ${ }^{2}$ and only rarely in other connective tissue diseases. ${ }^{2}{ }^{3}$ It has long been recognised that a subset of patients with myositis have other features such as serositis and Raynaud's phenomenon, but, until a recent report associating anti-Jo-1 antibody with interstitial pulmonary fibrosis, ${ }^{4}$ lung disease was thought to be uncommon. ${ }^{5}$ 


\section{Patients and methods}

Serum was obtained from 138 patients with myositis or cryptogenic fibrosing alveolitis, and the case notes were reviewed. Myositis was defined as proximal muscle weakness with at least two further abnormalities among muscle enzymes, the electromyogram, a muscle biopsy specimen, and dermatomyositis rash. ${ }^{6}$ Cryptogenic fibrosing alveolitis was diagnosed on the basis of persistent bilateral shadowing in the chest radiograph together with persistent crepitations on auscultation. ${ }^{7}$ In 25 cases the diagnosis was confirmed by open or drill lung biopsy. ${ }^{7}$ Among the 76 patients with myositis there were two with radiological evidence of pulmonary fibrosis but no record of crepitations being heard and no biopsy carried out; in these two cases the diagnosis of cryptogenic fibrosing alveolitis was provisional. In four further cases the chest radiograph was not available, and these patients were excluded from the statistical analysis. Lung function was studied in most cases, but sophisticated tests of the strength of respiratory muscle were generally not available at the time.

Anti-Jo-1 antibody was identified by counterimmunoelectrophoresis using rabbit thymus extract as the source of antigen ${ }^{8}$ and confirmed by immunoprecipitation of the protein antigen with transfer RNA from radiolabelled HeLa cell extracts. ${ }^{13}$ Control groups comprised 70 healthy subjects and about 1000 patients with various forms of systemic rheumatic and autoimmune disease. ${ }^{3}$

\section{Results}

Anti-Jo-1 antibody was detected in 20 cases. All but two patients had myositis, and 15 of the 19 with adequate clinical and radiographic data had cryptogenic fibrosing alveolitis. Anti-Jo-1 was detected in 13 of the 19 patients $(68 \%$ ) with both myositis and lung disease but in only two of the $62(3 \%)$ with cryptogenic fibrosing alveolitis alone and four of the $53(8 \%)$ with myositis alone $\left(\chi^{2}=41\right.$ and 30 , respectively; $\mathrm{p}<0.0001)$. Four patients positive for anti-Jo-1 antibody who had

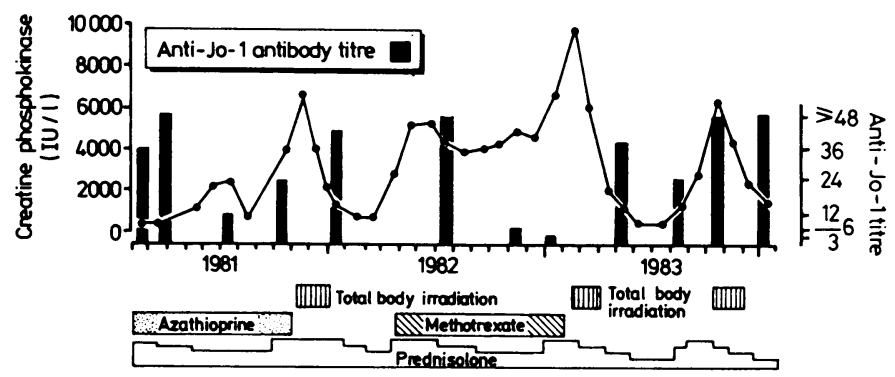

Titre of anti-Jo- 1 antibody in a 48 year old labourer with a 12 year history of arthritis and Raynaud's phenomenon and a four year history of myositis and pulmonary fibrosis; the titre correlated poorly with disease activity and treatment. (The creatine phosphokinase activity closely mirrored muscle strength as measured by myometer. ${ }^{10}$ )

cryptogenic fibrosing alveolitis (including the two with cryptogenic fibrosing alveolitis alone) had sclerodactyly; among 18 of the patients who were positive for anti-Jo-1 antibody other features such as Raynaud's phenomenon (16 patients), the sicca syndrome (10), and mild arthropathy (10) were considerably more common than they were among the patients with myositis or cryptogenic fibrosing alveolitis who were negative for the antibody. In addition, one patient had glomerulonephritis, two had dermatomyositis, and one had psoriasis. Ten children with myositis and six adults with underlying cancer were included in the study; all had myositis without cryptogenic fibrosing alveolitis, and none had anti-Jo-l antibody. Anti-Jo-l antibody was detected in only two of 300 patients with systemic lupus erythematosus, in which auto-antibodies abound. The prevalence of the antibody was also under $2 \%$ in patients with systemic sclerosis, which was surprising as myositis and pulmonary fibrosis concur more commonly than in $2 \%$ of cases of this condition. Indeed, three of the six patients with myositis and cryptogenic fibrosing alveolitis who were negative for anti-Jo-l antibody had systemic sclerosis.

Six of the 20 patients with anti-Jo-1 antibody presented with cough or dyspnoea; the remaining 14 presented with weakness or arthritis.
The underlying diagnoses made were of systemic lupus erythematosus (two), CRST syndrome (calcinosis, Raynaud's phenomenon, sclerodactyly, telangiectasia) (one), dermatomyositis (two), and polymyositis (12). The use of cytotoxic drugs is occasionally complicated by sitis (12). The use of cytotoxic drugs is occasionally complicated by pulmonary fibrosis, but data available on 14 of the 19 patients with myositis and cryptogenic fibrosing alveolitis showed that such treatment, if used, was started after the onset of lung disease. Cigarette smoking may play a part in rheumatoid lung disease, ${ }^{9}$ but several of our patients with myositis and cryptogenic fibrosing alveolitis were non-smokers.

One patient died of massive pulmonary fibrosis; the others had varying degrees of lung disease. The myositis also varied in severity but was particularly aggressive and resistant to conventional treatment in three patients who were selected for total body irradiation. In these cases the titre of anti-Jo-1 antibody fluctuated without relation to disease activity or treatment (figure). None of our patients was studied before the onset of disease, but in two patients with cryptogenic fibrosing alveolitis the antibody was present at least a year before myositis was diagnosed, and in one case of myositis without cryptogenic fibrosing alveolitis the antibody remained detectable during prolonged remission.

\section{Discussion}

The close relation between a syndrome of myositis plus fibrosing alveolitis and the presence of an autoantibody to a ubiquitous intracellular enzyme raises fundamental as well as clinical questions. The pathogenesis of myositis is thought to be mediated by cellular rather than humoral immune mechanisms, so, apart from having a possible role in the accompanying mild immune complex deposition, anti-Jo-l antibody is perhaps just an epiphenomenon-though an informative one for aetiology. Coxsackie B, a picornavirus, has been implicated in the cause of myositis, and the RNA of a related murine picornavirus interacts with histidyl-tRNA synthetase (the Jo-l antigen). Such a combination of host protein with RNA from a myotropic virus such as Coxsackie might well generate an autoimmune response (in susceptible people) and explain the link between antibody and disease. ${ }^{1}$

To the clinician anti-Jo-1 antibody offers a simple addition to the usual investigations for myositis, as these can be misleading, particularly when steroid treatment complicates the picture. Of the many types of autoantibody now recognised in myositis, ${ }^{3} 11$ at least two others (anti-RNP and anti-PM-Scl) are associated with additional rheumatological features, but anti-Jo-l most closely marks the important minority of patients with pulmonary disease.

This work was supported in part by a grant to MBM from the Muscular Dystrophy Association and by a travel grant from NATO.

\section{References}

Mathews MB, Bernstein RM. Myositis autoantibody inhibits histidyl-tRNA synthetase: a model for autoimmunity. Nature 1983;304:177-9. Nishikai M, Reichlin M. Heterogeneity of precipitating antibody systems in polymyositis and dermatomyositis. Characterization of the Jo-1 antibody system. Arthritis Rheum 1979;23:881-8.

${ }^{3}$ Bernstein RM, Bunn CC, Hughes GRV, Francoeur AM, Mathews MB. Cellular protein and RNA antigens in autoimmune disease. Mol Biol Med (in press). oshida S, Akizuki M, Mimori T, Yamagata H, Inada S, Homma M. The precipitating antibody to an acidic nuclear protein antigen, the Jo-1, in conpulmonary fibrosis. Arthritis Rheum 1983;26:604-11.

${ }^{5}$ Schwarz MI, Matthay RA, Sahn SA, Stanford RE, Marmorstein BL, Scheinborn DJ. Interstitial lung disease in polymyositis and dermatomyositis: analysis of six cases and review of the literature. Medicine (Balt) 1976;55:89-104.

6 Bohan A, Peter JB. Polymyositis and dermatomyositis. N Engl f Med 1975 ;292: 344-7, 403-7.

T Turner-Warwick M, Burrows B, Johnson A. Cryptogenic fibrosing alveolitis: clinical features and their influence on survival. Thorax 1980;35:171-80.

Bernstein RM, Bunn CC, Hughes GRV. Identification of antibodies to acidic antigens by counterimmunoelectrophoresis. Ann Rheum Dis 1982;41 :554-5.

Hyland RH, Gordon DA, Broder I, et al. A systematic controlled study of pulmonary abnormalities in rheumatoid arthritis. $\mathcal{F}$ Rheumatol 1983;10:395-405. from polymyositis after total body irradiation. Br Med 7 1982;284:1915-6. from polymyositis after total body irradiation. Br Med f 1982;284:1915-6. polymyositis. Arthritis Rheum 1983;26:s67. Rheum 1983;26:s67. 